Bond University

Research Repository

Technology considerations in health professions and clinical education

Moro, Christian; Stromberga, Zane; Birt, James R.

Published in:

Clinical Education for the Health Professions: Theory and Practice

DOI:

10.1007/978-981-13-6106-7_118-1

Licence:

Other

Link to output in Bond University research repository.

Recommended citation(APA):

Moro, C., Stromberga, Z., \& Birt, J. R. (2020). Technology considerations in health professions and clinical education. In D. Nestel, G. Reedy, L. McKenna, \& S. Gough (Eds.), Clinical Education for the Health

Professions: Theory and Practice (pp. 1-25). Springer. https://doi.org/10.1007/978-981-13-6106-7_118-1

\footnotetext{
General rights

Copyright and moral rights for the publications made accessible in the public portal are retained by the authors and/or other copyright owners and it is a condition of accessing publications that users recognise and abide by the legal requirements associated with these rights.
}

For more information, or if you believe that this document breaches copyright, please contact the Bond University research repository coordinator. 


\section{Chapter Title}

Technology considerations in health professions and clinical education

\section{Authors}

Dr Christian Moro, BSc, BEd, MBus, PhD, SFHEA

Faculty of Health Sciences and Medicine, Bond University, Gold Coast, Queensland 4229, Australia

Email: cmoro@bond.edu.au.

ORCID ID: https://orcid.org/0000-0003-2190-8301

Zane Stromberga BBiomSci (Hons)

Faculty of Health Sciences and Medicine, Bond University, Gold Coast, Queensland 4229, Australia

Email: zstrombe@bond.edu.au.

ORCID ID: https://orcid.org/0000-0003-1896-7300

Dr James Birt BIT (Hons), PhD

Faculty of Society and Design,

Bond University, Gold Coast, Queensland 4229, Australia

Email: jbirt@bond.edu.au

ORCID ID: https://orcid.org/0000-0002-0422-4867

\section{Overview:}

Learning methods and pedagogy is shifting in clinical education. Incorporating technology in education is especially important for training health professionals, where the necessary knowledge acquisition is typically much more experiential, self-directed, and hands-on than in many other disciplines. Virtual or mixed reality interventions are becoming more accessible, and can be delivered through various modes in a way that integrates directly into learning environments. However, there are often limits to the capacity of the technology, leaving educators unclear of which technologies are useful, and how they can be integrated into the learning environment. This chapter provides an overview of virtual and augmented reality; holograms and mixed reality; virtual dissection tables; social media; mobile applications and devices; 3D printing; online hosted video; simulation with technology enhanced learning; serious games; e-learning and audience response software. We provide insight into the use of technology in health professions and clinical education by defining the types of technologies and exploring published use-cases for these technologies across disciplines.

\section{Keywords:}

Virtual Reality; Mixed Reality; Augmented Reality; Clinical Education; Technology Enhanced Learning; Medicine; Medical Education; Blended Learning. 


\section{Introduction}

Health professional educators are continuously incorporating technology in their pedagogical practices to enhance their ability to teach relevant, up-to-date content in an ever-changing environment. This chapter provides an overview of relevant research surrounding some of these technological interventions. This includes virtual and augmented reality; holograms and mixed reality; virtual dissection tables; social media; mobile applications and devices; 3D printing; online hosted video; simulation with technology enhanced learning; serious games; e-learning and audience response software. We share published use-cases, research manuscripts and reviews to highlight the breadth and depth of technology used in clinical health education. A literature search of different electronic databases was conducted using the following terms: (education OR training OR skills) AND (clinical OR health OR medical) AND (technology OR computer OR device OR simulation). As the focus of this chapter is on the current generation of educational technology, the search was limited to studies published between 2009 to 2019. This is not an exhaustive literature review but rather representational across different technologies and clinical education disciplines using qualitative synthesis. The core technologies identified include mobile applications/devices, 3D printing, video, simulation trainers with haptic devices, serious games, social media, e-learning, audience response and XR (virtual reality, augmented reality and mixed reality).

\section{Technology in Health Education}

\section{Virtual and Augmented Reality}

One of the primary concepts when learning physiology or anatomy is the relationships of structures in 3D space. Traditionally, cadavers or silicon models have been used to provide 3D representations as a supplement to textbook material. Developments in computing hardware and software can now allow the entire human body to be rendered in anatomically correct environments within virtual or augmented reality (Figure 1). Both virtual and augmented reality applications have shown to be effective in enhancing the learning experience in various health profession courses (Birt et al., 2018, Moro et al., 2017a, Moro et al., 2017b) while also providing educators additional supplementary methods to engage students.

For clarity, the terminology in this review is adapted from Moro et al. (2017a):

- Virtual reality: The user's senses (sight, hearing and motion) are fully immersed in a synthetic environment that mimics the properties of the real world through high resolution, high refresh rate head-mounted displays, stereo headphones and motion-tracking systems. 
- Augmented reality: Using a camera and screen (i.e. smartphone or tablet) digital models are superimposed into the real-world. The user is then able to interact with both the real and virtual elements of their surrounding environment.

- Three-dimensional tablet displays: Using high-resolution screens on tablets and smartphones to visualise 3D models and environments. The user interacts with digital aspects on the screen and manipulates objects using a mouse or finger gestures.

Virtual reality can be applied to help students learn and practice across in a variety of real-life scenarios. Virtual patients can be rendered on a screen, with cameras and microphones tracking the trainees' facial expressions, eye gazes, head poses, and vocal cues (Kuehn, 2018). The virtual space is not only useful for learning, but also for practising engagement, assessments of interpersonal interactions and real-world scenarios. In virtual reality, one limiting feature is that the learner is entirely immersed in the environment, making it difficult to take notes, ask questions, or be fully interactive with the teaching staff or other students in the area. In order to revise after the lesson, it is often difficult to get back into the same environment, and as such, some students do not find it as useful for learning as other methods (Moro et al., 2017b).

Augmented reality allows the opportunity to provide 3D interactive resources outside the classroom, such as that utilised in paramedic distance education (Birt et al., 2017) or enhance anatomy learning content (Moro et al., 2017a). It can also assist in training teachers (Sural, 2018), create clinical scenarios (Sutherland et al., 2019), or enhance training for specific health professions such as radiation oncology (Jin et al., 2017). One benefit of augmented reality is the ability for consumer-level smartphones or tablets to render models in 3D. Therefore, students can learn from a range of readily available applications with no additional hardware requirements (Delello et al., 2015). However, augmented reality is limited by the capabilities of the smartphone/tablet and its built-in camera. In some cases, the mobile device camera does not recognise the objects correctly, and valuable in-class learning time is spent managing technological issues. 


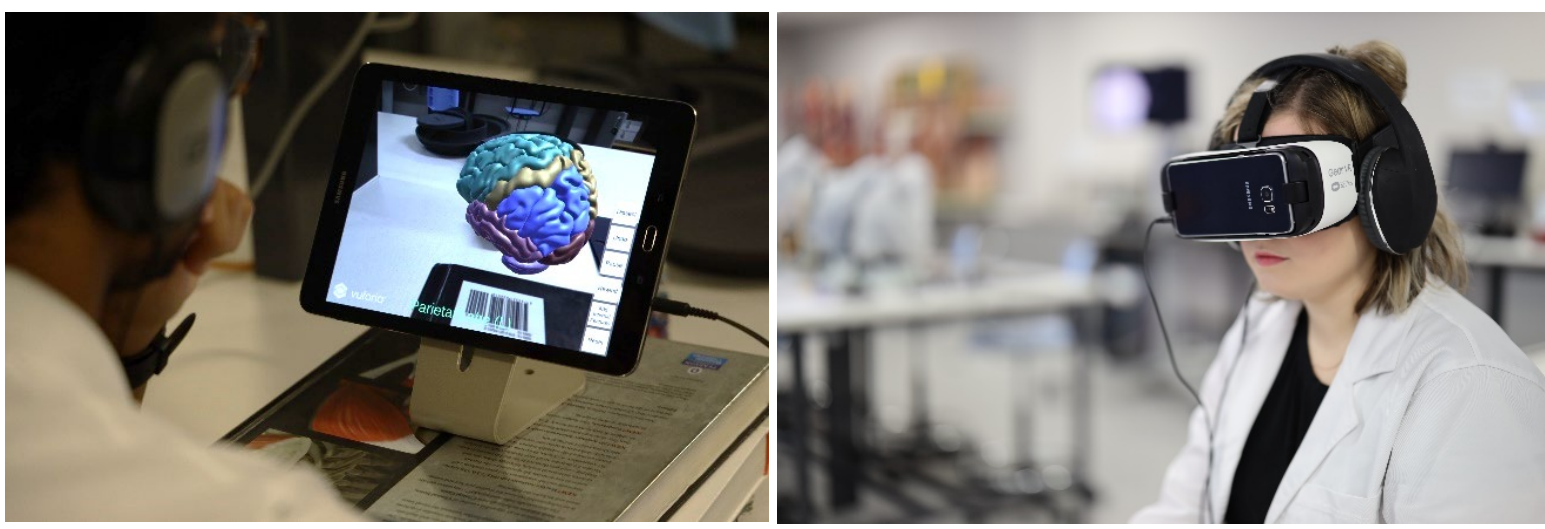

Figure 1: Biomedical science students using augmented reality (left) and virtual reality (right) to explore regions of the human brain (Photo: C.Moro).

\section{Holograms and Mixed Reality}

A blending of virtual and augmented reality is possible through new devices such as the Microsoft HoloLens 2. This device enables virtual environments and models to be rendered as 'holograms' within the user's visual space (Cowling and Moro, 2019). Most of these products are still in the developerlevel stage, and not yet widely available to consumers, although this technology does offer some potential benefits for future students in health education courses. The mixing of real and virtual worlds should reduce the levels of cybersickness or blurred-vision reported in many virtual reality applications (Moro et al., 2017b), while also allowing the learner to visualise components of the human body in complete 3D (Figure 2).

While this technology is still relatively new, it shows a great promise in increasing the student's initiative to pursue learning, ability to understand abstract concepts and promotes academic performance (Liu et al., 2019). Holograms provide a new student-centred teaching model which can incorporate gestures, voice commands, interactions with models and viewpoint tracking technology (Moro and Gregory, 2019). While still new, and with only developer kits being used in universities at the moment, this holographic technology is poised to bridge the gap between augmented and virtual reality. The learner's hands are free to take notes and interact with others in the class, as well as engage with the educator. Future research and published used-cases for these all-in-one holographic devices will provide more insights into the overall effectiveness of this mode for learning. 


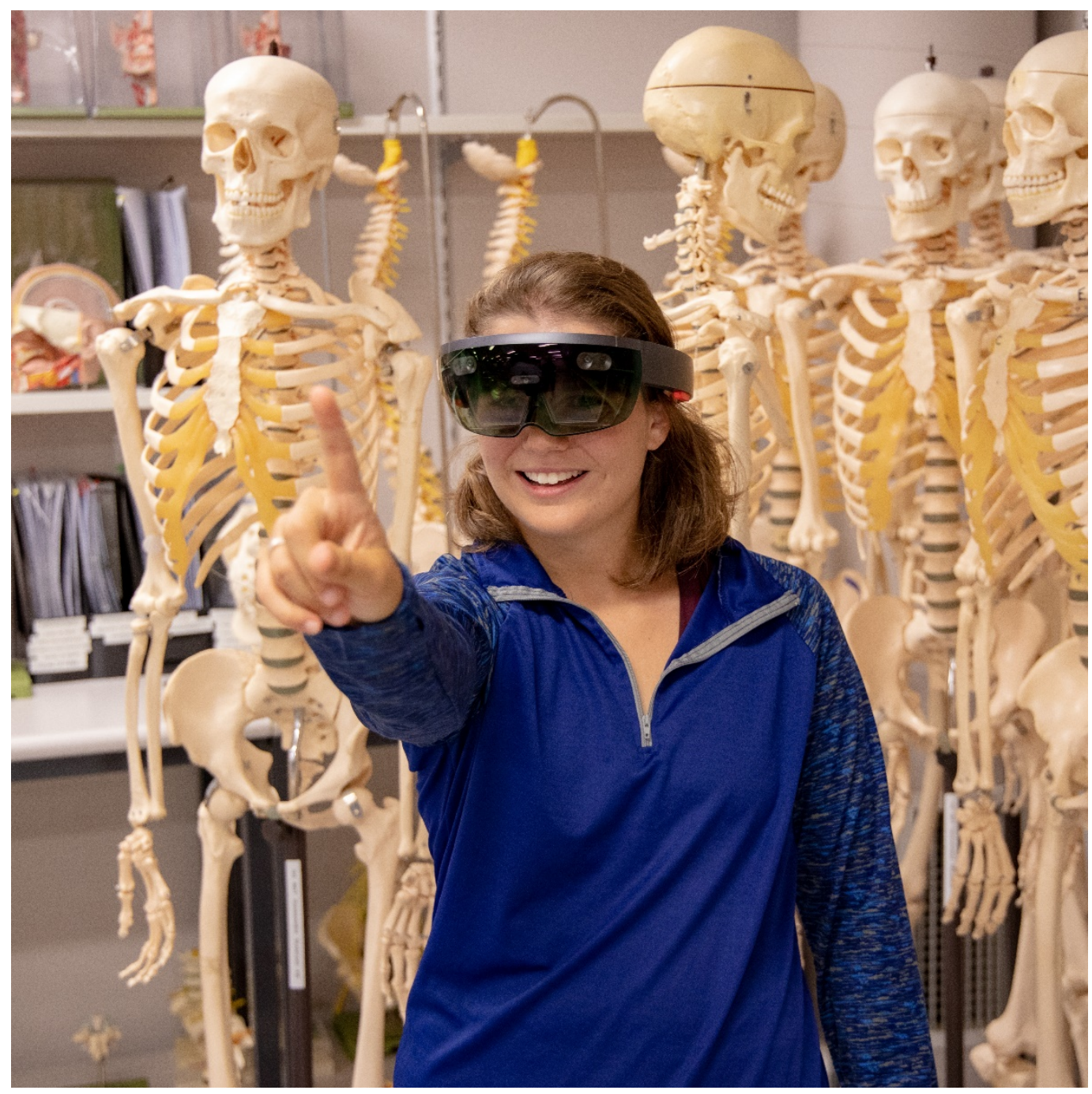

Figure 2: An exercise and sports science student uses voice commands and gestures within the Microsoft Hololens to visualise and interact with the muscular system of the body in 3D space (Photo: C.Moro).

\section{Virtual Dissection Tables}

While cadaveric dissection remains the primary method for teaching human anatomy, a range of hands-on digital multimedia devices are increasingly used to enhance the learning experience (Hosseini et al., 2018). A relatively new way to learn anatomy is in the form of virtual dissection tables. These tables have the potential to enhance the ability of learners to explore different anatomical components with ease (Moro and Periya, 2019), and can significantly assist in the diverse cohort of life sciences students, including a mix of undergraduate and postgraduate students within nursing, physiotherapy and dentistry courses (Narnaware and Neumeier, 2019, Moro and Periya, 2019). However, it is still uncertain if these technological supplements adequately prepare students for the workplace compared to traditional teaching methods (Moro and McLean, 2017). 
The optimal methods appear to be for virtual tables to be used in conjunction with the cadaveric dissections (Ramsey-Stewart et al., 2010, Azer and Eizenberg, 2007, Mathiowetz et al., 2016). Blending this technology with traditional teaching modes has provided educators with more options to facilitate learning. Virtual dissection tables have also shown great promise in many health professional courses, such as where $94 \%$ of medical imaging students reported benefits from the use of a virtual dissection table for anatomy study (Custer and Michael, 2015), and 90\% of neuroanatomy students reporting the same (Anand and Singel, 2017). In a review of fourteen studies comparing different teaching approaches including dissection, prosection and online computer-based teaching aids, it is still not clear if the supplementary methods for learning anatomy are entirely useful, and commented that more sophisticated research designs are necessary before evidence-based teaching practices can occur (Winkelmann, 2007).

\section{Social Media}

While social media is widely used by nearly all students studying within a higher education setting, it is not often integrated into curricula by educators (Chugh and Ruhi, 2018). Therefore, there is a lack of research detailing the benefits of incorporating social media and its potential uses. Sterling et al. (2017) systematically appraised 29 peer-reviewed papers on the use of social media in medical education. The authors found that twitter, podcasts and blogs were the most frequent social media strategies used to engage learners and enhance educational practice. YouTube and wikis were commonly used to teach skills and promote self-efficacy. Most studies were exploratory, highlighting privacy and online behaviour within the professional context of health. However, the effect of social media in education was deemed mixed at best, with the quality of studies considered as modest. A systematic review of social media in nursing and midwifery education (O'Connor et al., 2018) highlighted benefits of implementing social media in nursing curricula. For example, allowing information to be shared in real-time, supporting a student-centred learning setting and enhancing collaborative learning.

Hanson et al. (2011) assessed the use of social media as a means to improve health promotion using a survey $(n=503)$. The authors found that many health educators are using social media within education practice and highlight positive support of health education through social media. However, specific guidelines should be in place to attain best practice. In particular, four key constructions were recommended, including (1) performance expectancy or the degree to which an individual believes that using the system with help in job performance, (2) effort expectancy or ease associated with 
system use, (3) social influence or the perception of importance others believe in system use, and (4) facilitating conditions, or the degree to which an organisation has the technical infrastructure to support use. It was found that the majority of individuals use social media personally, but few of them use it for work-related purposes because the business blocks social media use. The authors found that older educators lack the belief that using social media enhance job performance and those that perceive social media as positive are already users of social media themselves.

In medical education, Cheston et al. (2013) conducted a systematic review on the use of social media and found fourteen studies that noted enhancement in knowledge (exam scores), attitudes (empathy)

and skills (e.g. reflective writing). However, the authors pointed out that these studies were of low to moderate quality and that further investigations in this field are required. Overall, the use of social media in education offers an excellent medium for health-care professionals to share information and promote collaboration among its users. However, as information on social media can be added by anyone, the content should be monitored and assessed for quality (Moorhead et al., 2013). Furthermore, privacy and confidentiality should be considered, as the general public is generally unaware of the consequences of sharing personal information online (Adams, 2010).

\section{Mobile applications/devices}

The potential of mobile devices, such as smartphones and tablets, to aid learning in a health profession education setting is clearly evident. These devices are capable of providing easy access to a wide variety of educational resources to support learning, such as virtual anatomy models and electronic books. Pimmer et al. (2016) provided a systematic review of 36 empirical papers that analysed mobile and ubiquitous learning across disciplines in higher education to determine what types of mobile learning exist and explore the capabilities of mobile devices for facilitating practice and active learning. It was identified that health education and medicine are the dominant categories that have investigated the use of mobile learning.

Mobile devices can facilitate personalised, distributed and more frequent practice allowing the hybrid design of education where learners can create multimodal representations of study material. This, in turn, can assist with reflective practice in both formal and informal learning situations leading to improved learning outcomes. The authors recommend more collaborative design between end-users and developers. Collaboration between learners that use social media allows for more informal education connecting prior knowledge, private lives and formal didactic education design. In 
undergraduate nursing education, O'Connor and Andrews (2015) critically reviewed 24 studies on the use of mobile handheld technology to address challenges related to the theory-practice gap, lack of clinical supervision and ad hoc learning in clinical environments. The authors found that most of the analysed papers were exploratory adopting mixed methods to assess education effectiveness with most reporting improved efficiency, learning scaffolding, enhanced knowledge and skills and decision making. However, the authors indicated that there was no clear definition of mobile technology across the literature making it difficult to make specific comparisons between the technological devices that can be hand-held.

A systematic review conducted by Kim and Park (2019) reviewed eleven randomised and nonrandomised controlled trials published between 2011 and 2017 that evaluated the effects of smartphone-based mobile learning for nurses and nursing students and meta-analysed ten of them to analyse the effect sizes. Smartphone mobile learning was determined to be an effective tool that positively improved knowledge, skills, confidence and attitude towards learning, however it did not affect cognitive load and satisfaction with learning.

Using a survey of 29 questions on the Technology Acceptance Model (TAM), Briz-Ponce and GarcíaPeñalvo (2015) recruited 124 participants to quantify acceptance of using mobile technology applications in medical education across both undergraduate medical students and practising clinicians. It was found that self-efficacy (ability to complete the tasks with the technology) and recommendation (a measure of mobile technology recommendation) are the strongest indicators of behavioural intention to use the technology. The authors concluded that as the number of mobile applications increases, the task of determining the effective use of these applications for medical education will become more challenging. It was recommended that future studies explore data using subgroups such as age, gender and profile to gain deeper insights into the impact of these variables in the learning process.

Klímová (2018) reviewed ten randomised controlled trials published between 2010 and 2017 that evaluated the use of mobile learning in medical education (those currently studying medicine, as well as doctors and other healthcare professionals). The author established that mobile learning is efficient and beneficial in the acquisition of new knowledge and skills and is perceived to be as an appropriate compliment to traditional learning methods. A qualitative systematic review conducted by Lall et al. (2019) sought out to determine the views of educators and learners on using mobile devices to aid learning and their perceived factors to enhance or hinder its implementation in medical and nursing 
education. The authors concluded that the portability of mobile devices can enhance interactions between the learners and the study material, fellow learners and educators in various health professions. Some of the limitations of mobile devices are that they need to be implemented within the institution, as well as specialised training and support needed in order to fully comprehend the various options/functions of the devices

\section{D Printing}

Three-dimensional (3D) printing is increasingly gaining recognition as a tool to enhance both healthcare education and practice (Figure 3). Malik et al. (2015) analysed 93 articles to highlight the uses of 3D printing in surgical practice and medical education. Specifically, 3D printing was identified as useful in education and clinical training across a number of disciplines, including orthopaedics (to understand injuries of the musculoskeletal system), physiotherapy (to assess complicated anatomy), and for surgeons (to discuss deformity with patients). As anatomy is taught early-on in most health profession and clinical education curricula, means that the ability to 3D print human anatomical concepts and models can be of great use in a broad range of applications. It can be useful as a patientlearning device, such as to obtain informed consent for management of complex fractures, or for easing understanding in patients and their families before interventions or procedures. Physiotherapists can further explain concepts to their clients surrounding muscle and joint movements, or dentists can 3D print structures to show how fillings or alterations to the teeth can impact the jawline.

Virtual anatomical models can also be kept to create catalogues of pathology for educational purposes. These models can be used for anatomy learners and in training on rare complications or decision-making for high-risk patients. Some of the limitations are related to a single type of material used in cheap 3D printing with an inability to simulate soft and hard tissues. Therefore, multi-material printers should be used to develop higher fidelity reproductions. Fine detailed structures are also challenging to create but, when designed correctly, can allow opportunities for complex visualisations used in neurosurgery training to allow for safe environments to practice operating on patients. 3D printing can also be used effectively to familiarise learners with surgical instruments. Malik et al. (2015) concluded that 3D printing allows for creative innovation within the surgical landscape, not just in training but also in practice with the future towards reconstruction and transplants.

To further assess the usefulness of 3D printed models, Jones et al. (2016) used a qualitative survey on 51 medical students to explore the use of 3D printed anatomical models to enhance surgical education 
and clinical practice. The fabricated models were created through a process of converting detailed $\mathrm{MRI}, \mathrm{CT}$, ultrasound and mammogram data into printable 3D mesh models. Participants highlighted the usefulness of model integration into medical school curriculum but had concerns over the fabrication cost related to the model realism and the lack of sensory (haptic) feedback. It was highlighted by the authors that clinical use would require near-exact replicas of diseased human organs. To that end, it was suggested that future work needs to explore not only visual fidelity but also haptic fidelity. Future models should be fabricated with tactility by a combination of moulds, printing and materials.

There have been several research studies that have compared the use of $3 \mathrm{D}$ printed anatomical models with more traditional learning methods, such as using cadavers and didactic lectures. In a double-blind randomised control trial where pre- and post-testing was used (Lim et al., 2016), the authors compared traditional external cardiac cadaveric anatomy with 3D printed models to determine the effectiveness of 3D printing for self-directed anatomy learning. The 3D models were created using computed tomography (CT) and surface scanning of the heart anatomy, including vessels, vasculature, projections and sulci. In this study, the authors split 52 participants across three groups to compare anatomy learning using cadaveric materials, 3D printed models and combined materials (cadavers with 3D printed models). It was found that the group that used solely 3D printed models scored significantly higher in the post-test that evaluated anatomy recall than the other two groups. The authors concluded that 3D printed reproductions of anatomical structures have the potential to provide a readily available source of supplementary teaching materials. It was also noted that novice learners can be apprehensive when encountering cadaveric samples which promote the use of 3D printed models as a useful primer to induce familiarity and break down inhibitions before use of cadavers which the authors identified as essential in anatomy learning.

A study conducted by Su et al. (2018) designed and produced 3D printed models for congenital heart disease education. Sixty-three medical students participated in this study, where they were randomly allocated into two groups that participated in a medical seminar: the experimental group where 3D models were used and the control group without the 3D models. Assessment of the effectiveness of 3D printed models was conducted using subjective (self-assessment using a Likert-style questionnaire) and objective (multiple choice questions assessing knowledge acquisition and structural conceptualisation) methods. The results from the questionnaire showed that the feedback from experimental group was significantly more positive than from the students in the control group. Students in the experimental group had significantly better test results in structural conceptualisation when compared to the control group. 
In Cai et al. (2018) study, 35 first-year medical students were recruited to evaluate the effectiveness of using 3D printed structures to assist in learning human anatomy. Students were assigned to two learning groups, namely the didactic learning group and simulation group. In didactic learning group, students learned about the locking-unlocking of the knee joint through a didactic lecture $(n=18)$ where they were also provided with lecture notes and skeleton models to explain the content related to the knee joint. The simulation group $(n=17)$ were provided with the same textual content as the didactic group, however, instead of using the skeletons to explain knee joint mechanisms, tutors used 3D printed models. After 30 minutes, both groups were assessed using eleven multiple-choice questions, where students in the simulation group achieved significantly better results than the didactic learning group. There are some limitations of 3D printing, such as the lack of variety and tactile feedback compared using cadaveric material, or the fact that the plastic colours are not authentic when investigation anatomical body parts. However, as 3D printers increasingly enter the high school environment more and more students entering health professional fields will have prior experience with this technology, and this will become a commonplace and easy technology to utilise in learning.

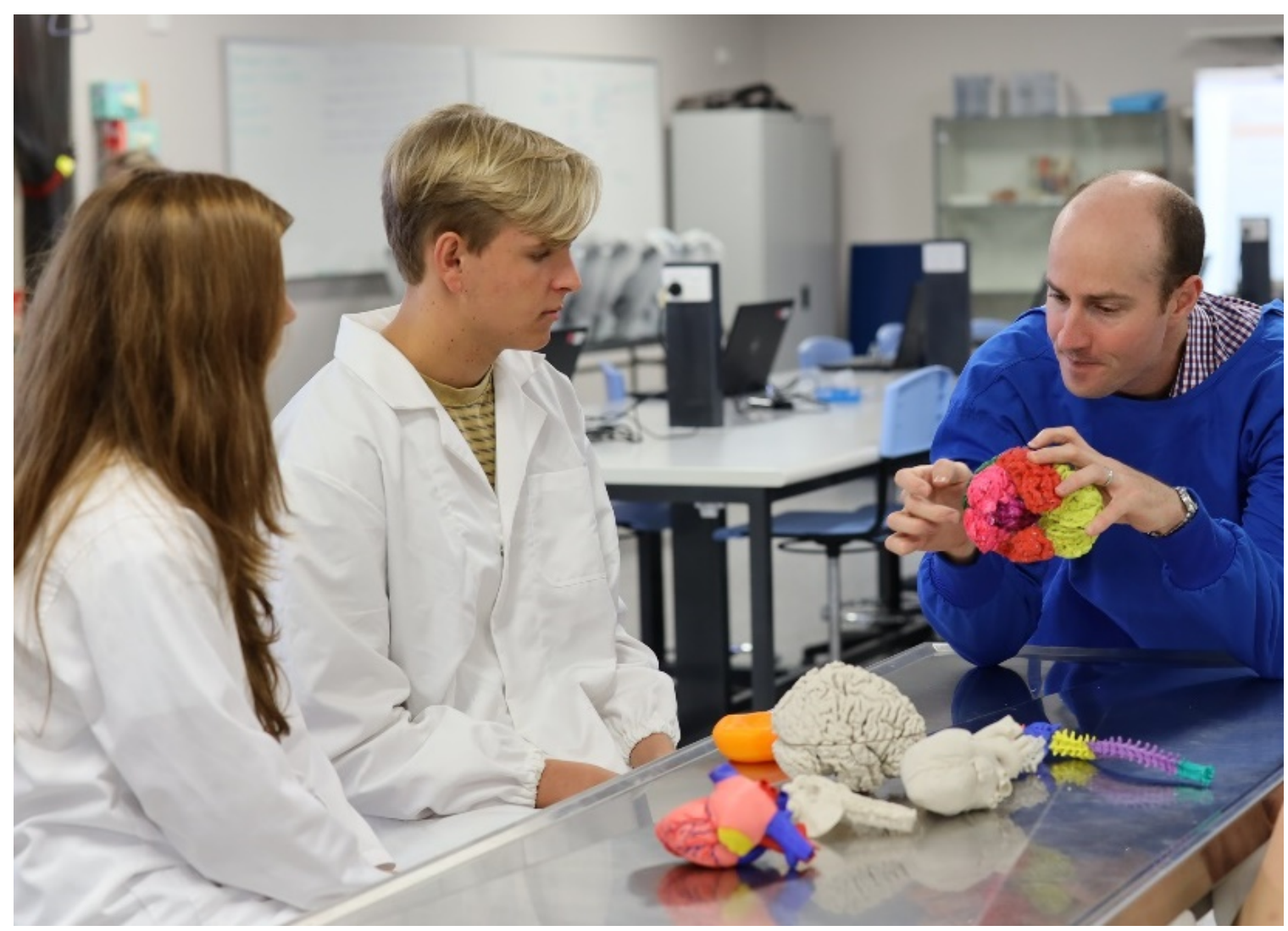

Figure 3: An educator instructs Biomedical and Exercise Science students on central nervous system anatomy using 3D-printed models (Photo: C.Moro). 


\section{Online-Hosted Video}

Another type of educational media that is capable of conveying information are videos. Tuong et al. (2014) conducted a systematic review from 1975 to 2012, looking at controlled clinical trials examining the effectiveness of video interventions in changing health behaviour. Critical analysis was performed on 28 articles where the video had an effect on modifying health behaviour. It was noted that videos are a less resource-intensive means of delivering educational content with the benefit of standardising educational delivery. Video has the added benefit of being administered in many forms, such as being live-streamed, available for download and having a physical copy of the material.

The downside of using videos as an educational tool is the lack of face-to-face counselling, which allows tailoring the content according to the needs of the patient. However, the benefits of easy content distribution offered by the use of videos can outweigh personalisation based on patient needs. Tuong et al. (2014) concluded that the benefits of video instruction include both short and long-term improvement to behaviour, including a reduction in smoking, self-examination and selfcare. There is a plethora of educational videos readily available of video-sharing sites such as YouTube; however, the quality of those videos is unclear.

Duncan et al. (2013) assessed 100 YouTube sites and approximately 25 hours' worth of content across ten common clinic skill-related topics. It is often expressed that YouTube and online video repository sites are perceived as "time wasters". The authors wanted to counter this argument by analysing YouTube sites focusing on the integration of clinical skills delivered through YouTube videos. It was identified that topics with the most significant number of videos and user views were related to common skills across the nursing or health-related disciplines such as "cardiopulmonary resuscitation" and more specialised topics such as "pain assessment" with fewer user views. There were concerns regarding the quality of videos with only $1 / 100$ videos analysed were categorised as "good". The conclusion was that there was a need for more rigorous evaluation, and educators were encouraged to be more proactive in the recommendation of suitable materials as supplementary tools to learning. It was also noted that lecturers would often recommend YouTube videos from credible sources such as the World Health Organisation, but independent and self-directed learners often stumbled across sources using the number of user views and likes as a guide to quality. Therefore, it could be said that YouTube is not about "time-wasting" but rather lack metrics that identify the quality of clinical education and learning. 
To aid educators in integrating videos in their teaching practices, Dong and Goh (2015) compiled a list of twelve tips. In this article, advantages of using videos in teaching were discussed, as well as the requirements for teachers wishing to integrate this technology, namely knowledge about the technology and ability to make informed decisions on video use. Educators were able to choose between using existing videos that are compatible with their teaching strategy, as well as produce their content. However, there is an added difficulty in creating videos themselves, as it often requires professional guidance and technical skill. Strategies towards the successful implementation of this technology in the classroom and the promotion of student engagement were also discussed. In simulations, video-assisted debriefing can enable students to reflect upon their conduct and allows educators to provide individualised assistant to each member of a cohort. This is increasingly prevalent in health professional education such as physiotherapy and nursing, and there is an increasing body of literature surrounding this process (Ali and Miller, 2018).

For educators, video content can be of great use when understanding which areas to focus on in teaching. For example, in physiotherapy students, a video-reflexive ethnography study identified the fact that students had only a limited ability to recognise errors during filmed clinical scenarios (Gough et al., 2016). As video equipment becomes cheaper and more accessible, and video content can be easily uploaded to learning management sites or online repositories, it is likely to see video becoming increasingly utilised in health profession courses.

\section{Simulations with Technology Enhanced Learning}

Technology-enhanced simulation training is becoming increasingly prevalent health care education and adds to current simulation training used in disciplines such as physiotherapy since the 1980s (Owen, 2016). Simulations provide a safe environment to practice skills before performing procedures in real life and are used in various scenarios, such as in postgraduate emergency on-call physiotherapists for their cardiorespiratory education (Gough et al., 2013). Simulated patients often work in real environments, but modern simulations are increasingly using technology-enhanced learning to create virtual patients, scenarios or environments. Cook et al. (2011) analysed 635 studies of simulation training in teaching laparoscopic surgery, gastrointestinal endoscopy, suturing skills, emergency resuscitation, team leadership, anatomical examination and others. The authors implied that technology-enhanced simulation training is associated with improved outcomes in comparison with no intervention for health care professionals, with only $4 \%$ of the analysed studies showing no increase in effect. Specifically, simulations lead to large positive gains with respect to knowledge use. 
The conclusion is that technology-enhanced simulation training has a large effect on knowledge, skills and clinician behaviour but less of an effect on patient care.

A bibliographic literature review of 24 high impact articles published between 2001 and 2011 identified four primary content areas of simulation use in medical education (Abraham et al., 2011): (i) background and history; (ii) procedural training and methods; (iii) quality and safety and (iv) teamwork and communication. Simulations within health education can focus on a spectrum of activities, including skill training, learning procedures, clinical diagnoses, and facilitating clinical process and teamwork. Specifically, simulation gives users the ability to 'hone their communication skills in a clinical setting' and provide 'scenario experience'. The ability to give and receive feedback while undertaking simulation training is invaluable in medical education. Simulation can be done individually or in teams through several different technologies available in both observation and interactive practice, and throughout its history has developed into an important learning method in contemporary health professions education (Owen, 2016, Gough, 2018). A qualitative systematic review covering literature between 2003-2009 identified which key variables were identified to inform on the best practices of using simulation-based practice in medical education teaching (McGaghie et al., 2010, Table 1).

Table 1: Twelve features that highlight the best practice in simulation-based medical education

\begin{tabular}{|l|l|l|l|l|l|}
\hline feedback & $\begin{array}{l}\text { deliberate } \\
\text { practise }\end{array}$ & $\begin{array}{l}\text { curriculum } \\
\text { integration }\end{array}$ & $\begin{array}{l}\text { outcome } \\
\text { measurement }\end{array}$ & $\begin{array}{l}\text { simulation } \\
\text { fidelity }\end{array}$ & $\begin{array}{l}\text { skill acquisition and } \\
\text { maintenance }\end{array}$ \\
\hline $\begin{array}{l}\text { mastery } \\
\text { learning }\end{array}$ & $\begin{array}{l}\text { transfer to } \\
\text { practice }\end{array}$ & team training & $\begin{array}{l}\text { high-stakes } \\
\text { testing }\end{array}$ & $\begin{array}{l}\text { instructor } \\
\text { training }\end{array}$ & $\begin{array}{l}\text { educational and } \\
\text { professional context }\end{array}$ \\
\hline
\end{tabular}

The authors concluded that simulation-based medical education is maturing, but more specific thematic analysis of the research is required. This study was followed up by a revisit of the review in 2016 (McGaghie et al., 2016) looking at high impact work from 2010 to 2015. The authors identified that:

(i) today's academic medical community educates twenty-first century physicians using nineteenth century thinking;

(ii) the medical education community needs to understand how technology contributes to educational effectiveness;

(iii) difficult to define a definitive account of simulation-based education as the topic is a moving target;

(iv) simulation is the highest-rated area of importance for medical education research;

(v) simulation technology is a key contributor to quality health professions education; 
(vi) integration of simulation into existing curricula is challenging;

(vii) simulation with mastery learning can produce powerful educational interventions that yield immediate and lasting results;

(viii) cost-effective and efficient simulation is a challenge when educating and evaluating individuals.

Cook et al. (2010a) analysed fifty studies on the use of virtual patients across different health and clinical education professions. They concluded that virtual patients (patients coded and rendered using 3D modelling and animations) are associated with improved learning outcomes compared with no intervention for medical, dental, nursing and other health-related professions. The authors indicated that there is no evidence that virtual patient simulation is superior to that of other training methods. However, it does assist with logistic barriers such as cost, distance learning and selfdirection. There is also evidence to support other beneficial impacts of using virtual reality for simulations in fields such as nursing, where it has helped to increase patient acuity, manage the high student-to-faculty ratios in some courses, while also minimising the risks to patients from untrained students (Jenson and Forsyth, 2012).

The quality and effectiveness of virtual patients or virtual worlds can vary in terms of their coding, design and implementation, which can lead to different learning outcomes. However, this impact can be minimised in fields such as nursing, by using a multidisciplinary approach when developing these resources (Kilmon et al., 2010). It is difficult to answer questions regarding design bias through metaanalytic studies and more work is required in direct qualitative comparisons of virtual patient design and user experience to better understand the effective use of virtual patients for training.

\section{Serious Games}

The development of computer technology and the accessibility of the internet has given rise to the use of serious games in higher education (Figure 4). Serious games or "games primarily focused on education rather than entertainment" (Miller et al., 2011) are especially useful for simulated training, knowledge acquisition, skills development and responsive narrative to convey meaning. Girard et al. (2013) explored the rapid growth of serious games by analysing learning effect and engagement in serious games identifying that serious games might be powerful tools for learning, but more empirical studies were required to investigate the effectiveness in learning. 
Boyle et al. (2016) analysed 143 articles published between 2009 and 2014, identifying positive outcomes of games in education. The authors explored specific game outcomes concerning learning, knowledge acquisition, motivation, perception, behavioural change and motor learning outcomes. The evidence indicated that there was a positive outcome from playing games. Simulation games were the most popular, allowing real-world replication and skills training. The most popular game genre was role-playing, followed by adventure games, strategy, problem-solving and puzzle games. It was identified that defining characteristics of a game was difficult when not classified as simulation and that constructs such as flow, engagement and appeal should be used more when defining games research for education. Although the focus was on STEM subjects, health education was identified as the most popular for application of serious gaming and game-based learning.

Ricciardi and De Paolis (2014) examined serious games developed specifically for health professions and health-related fields including surgery, odontology, nursing, cardiology, first aid, dietetics, psychology and more. They identified that serious gaming is a useful technology that improves learning and skills development but the number of case studies was limited with first aid having the highest number of developed serious games given the importance around continuous training which serious games can achieve at a low cost. The cost factor was reiterated by Knight et al. (2010) in a pragmatic control trial that explored the use of serious games in the teaching of major incident triage and compared it to with traditional training methods. Learners $(n=91)$ were randomly assigned into two training groups: a traditional major incident triage card-sorting group and a serious game simulation group. Traditionally, learners are taught triage using a combination of quick physiological assessment using a mobile four state priority ranking in small practical workshops where they either work with live actors or mannequins. The problem is that reconstructing these live triage events are costly and unrepeatable.

Additionally, practical restrictions often limit the degree to which activities can reflect real-world. In this study, a serious game case study was developed called triage trainer that allowed learners to play through a major incident scenario, triaging digital casualties. The results of the game showed that more causalities where triaged without an error using the serious game over the traditional card sort activity with no impact on time on task. It was recommended that feedback be improved in the serious game and that more involvement of the end-users is integrated earlier in the development process but that serious games are useful within medical education. Petit dit Dariel et al. (2013) examined the potential for serious games within nursing education, especially concerning clinical reasoning skills, 
complex problem solving and pedagogical solutions to develop these within simulated safe environments.

Wang et al. (2016), conducted a more recent systematic review of serious games in training health care professionals with 42 games included in the review. Specific points were made about the cost associated with simulated mannequin delivery in terms of human resources and simulator costs and the cheaper costs associated with serious games. Gorbanev et al. (2018) provided a similar conclusion, stating that serious games have the potential to disrupt the industry, especially as it pertains not only to training costs but also to patient care. A serious games example of patient care can be seen in Robert et al. (2014) with serious games recommended as a treatment for Alzheimer's disease and related ageing disorders. They have also been used widely in personal health care (McCallum, 2012) to prevent stress and manage pain and disease. What was noted by all articles was the complexity of building serious games, including the multidisciplinary teams required and the pilot nature of the studies. Additional concerns were raised by Gentry et al. (2019) noting that most serious games research has been conducted in high-income countries with the cost of serious gaming and devices being a barrier for use in low and middle-income countries which are the most affected by a worldwide shortage of trained health workers. It was also noted that serious gaming is an emerging field and more rigorous research is required to compare serious games with controls including longitudinal patient outcomes, participant behaviour, attitudes and adverse effects.
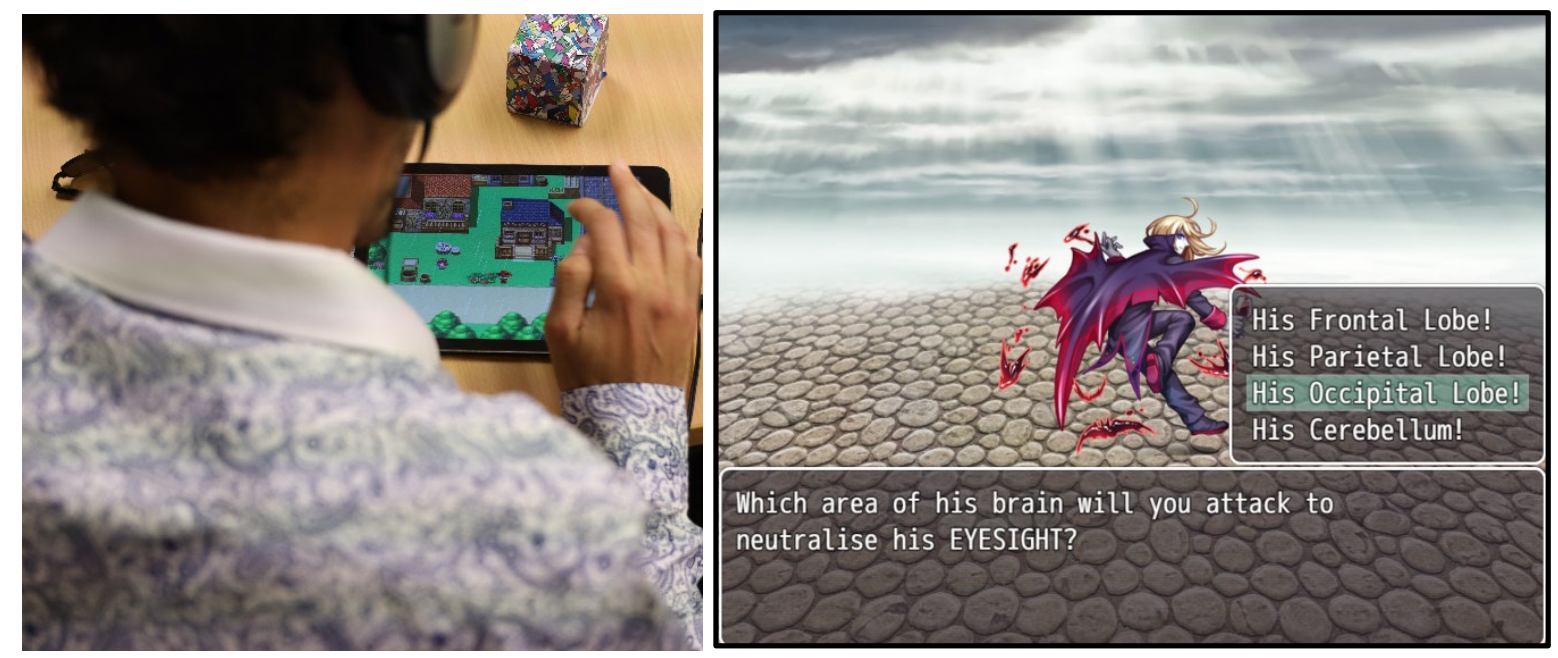

Figure 4: A student revises using “The King's Request: Anatomy and Physiology Revision Game”, a free game available online for learning within health professional education (Images: C.Moro). 
Internet-based learning in health and medical education is rapidly growing. Being aware of the available technologies and how they are used to aid learning in a higher education setting is integral for understanding how the learner interacts with the study content (Moro and Kinash, 2012). Cook et al. (2010b) conducted a systematic review to describe in detail the variations in configuration, instructional methods and presentation elements in internet-based courses. Authors found that $89 \%$ of 266 studies included in this review used written text, and 55\% used multimedia as a means to present educational content via web delivery. It was found that $24 \%$ of the studies used bot webbased and non-computer-based instructions. Specifically, in web-based courses, most employed specific instructional methods like patient cases self-assessment questions and feedback as a means to enhance learning. Authors suggested that educators wishing to incorporate web-based learning in the curriculum should consider a broad range of available web-based learning configurations and methods before choosing a specific approach.

Wong et al. (2010) conducted a qualitative systematic review of 249 research papers to produce a theory-based guide for developing and evaluating internet-based courses for clinical doctors and medical students. In this review, the authors sought to explain what type of internet-based education 'works', produce a guideline for course developers and extended the methodological knowledge base in medical education research. The review of the research articles presented two main findings: internet-based courses must be engaging to the user and interactivity is highly regarded. Additionally, while course design is a crucial factor in internet-based courses, special attention must also be paid to course-context interaction. One group might perceive a particular course as highly useful in one context, whereas a different group would find the same course much less useful in a different context. The authors suggest that educators wishing to implement internet-based learning should address a set of questions to increase the chances of their courses of being perceived and useful and provide an effective learning platform. These findings are consistent with similar studies demonstrating the benefits of e-books in facilitating learning in anatomy (Stirling and Birt, 2014).

George et al. (2014) identified sixty randomised controlled trials published between 2000 and 2013 that focused on the learner's knowledge, skills, satisfactory and attitudes towards e-learning in health education. The findings were based on the comparison between e-learning and traditional learning methods or between different modes of e-learning. The authors found that e-learning was found to be more effective than traditional learning in terms of knowledge and skills gained. Specifically, $29 \%$ of studies showed significantly higher knowledge acquisition, $40 \%$ showed significantly higher skill gain and $14 \%$ showed higher satisfaction with e-learning when compared to traditional learning. The 
evidence from this review suggests that e-learning is equivalent and sometimes even more effective than traditional learning in terms of knowledge and skills acquisition. Furthermore, e-learning provides a convenient and cost-effective alternative to conventional learning. Specifically, a systematic review conducted by Jayakumar et al. (2015) that evaluated the use of e-learning in surgical education demonstrated a variety of different learning material can be delivered through this medium, including case-based, theoretical knowledge and surgical skills teaching. Out of the thirtyeight articles that were included in this review, most reported significant knowledge gain from elearning. However, two in three studies did not compare the knowledge gain to a control group. These studies can function as a proof of concept of using e-learning in surgical education. Nevertheless, future work in this area should focus on using appropriately designed studies.

Maertens et al. (2016) conducted a systematic review of e-learning in surgical training, 87 randomised controlled trials were critically evaluated to establish the evidence supporting e-learning as a teaching tool compared with either no intervention or alternative teaching methods. This review showed that e-learning is a useful tool in aiding the development of different surgical skills. However, evidence supporting the superiority of e-learning to traditional methods is limited. Indeed, only two of the randomised controlled trials demonstrated transfer of skills to the clinical environment, however, there was no evidence that showed improvement in patient outcomes.

\section{Audience Response}

Audience response technology has been widely used among educators to enhance student classroom involvement and active engagement. It usually consists of devices controlled by the learner (for example 'clickers') which allows them to actively participate in the class by selecting responses to questions that are displayed of programs such as Microsoft PowerPoint and gaining instant feedback of the audience responses (for example, in a bar graph). Audience response can also be set up to allow students to provide questions as well as answers (Moro and Hensen, 2017). An in-depth meta-analysis of fifty-three research articles (overall sample of 26,095 students) on the effects of audience response systems on cognition was conducted by Hunsu et al. (2016). The authors determined that clickerbased technology only produced a small but significant effect on different cognitive learning outcomes and a near-medium impact on non-cognitive learning outcomes. Furthermore, these effects were deemed as non-existent for course material recall or retention. The authors suggested that instructors should design questions that require critical thinking, knowledge application and synthesis in order to meet higher order learning goals. However, these results should be interpreted with caution as $90 \%$ studies included in the analysis did not randomly assign participants into experimental and control 
groups as the studies were conducted on students in an already formed cohort. In addition, only $20 \%$ of the studies used measures of pre-test and post-test to establish the differences between participants at baseline. Indeed, a more substantial effect of using clicker-based technology was observed in studies where students were randomly assigned to experimental and control groups.

A systematic review and meta-analysis of twenty-one studies on the learning outcomes in health professional's education determined that 14 of the studies reported significant differences in knowledge scores in favour of the audience-response group. A meta-analysis of randomisedcontrolled trials revealed that there were no statistical differences in the knowledge scores between audience response and control groups, whereas non-randomised studies showed a significant difference (Nelson et al., 2012). Authors suggested that non-randomised studies over-estimated the impact of the audience response technology due to methodological limitations of their study design. Overall, the results obtained in this analysis were equivocal and more research with appropriate study design is required to draw definite conclusions. A follow-up systematic review conducted by Atlantis and Cheema (2015) three years after the publication of Nelson et al. (2012) review failed to support the hypothesis that audience response technologies have a significant effect on learning outcomes in health sciences and medical students and reiterated the need for more high-quality research in the area.

One primary benefit of audience response is that it allows students to respond in real-time. In health education courses, the students are often presented with the theoretical content in the first few years, before experiencing the practical aspects (i.e. in the field or hospital environment). This means that after performing well in early years, students may still feel unprepared for practice by the time they are due to enter the practical years (Moro et al., 2019). Through allowing the students to be put onthe-spot, where they are able to answer questions or interact in real time, this may assist in their confidence to discuss learned content infront of a client, or patient, out in the field, clinical or practical environment.

\section{Conclusion}

Technology use in health professional education is an exciting area of research. Educators face challenging decisions, such as which technology to incorporate in their teaching practices and which technology would work best for their students. It is apparent that further scholarship, research and investigation in this area is essential, with the need for greater diligence in research methodology within studies. These developments in the education landscape do show a great promise for the 
future, and potential enhancements in learning outcomes for health profession students. Two major hurdles exist for educators wishing to adopt more technology in their curricula. The first is the requirement for skill training in technology, and the second is the often difficulty in finding evidencebased approaches and research specific to their areas. This chapter has outlined a variety of research surrounding the benefits, use cases and limitations of technologies used in an attempt to enhance learning within health profession and clinical education. Although not all approaches are available to all programs, due to limited funds, access to technology or skilled staff, modern technology has introduced increasing options for educators wishing to enhance or alter their curriculum in a way that can improve student interactivity, engagement and learning.

References

ABRAHAM, J., WADE, D. M., O'CONNELL, K. A., DESHARNAIS, S. \& JACOBY, R. 2011. The Use of Simulation Training in Teaching Health Care Quality and Safety: An Annotated Bibliography. American Journal of Medical Quality, 26, 229-238.

ADAMS, S. A. 2010. Blog-based applications and health information: two case studies that illustrate important questions for Consumer Health Informatics (CHI) research. Int J Med Inform, 79, e89-96.

ALI, A. A. \& MILLER, E. T. 2018. Effectiveness of Video-Assisted Debriefing in Health Education: An Integrative Review. J Nurs Educ, 57, 14-20.

ANAND, M. \& SINGEL, T. 2017. A comparative study of learning with "anatomage" virtual dissection table versus traditional dissection method in neuroanatomy. Indian Journal of Clinical Anatomy and Physiology, 4, 177-180.

ATLANTIS, E. \& CHEEMA, B. S. 2015. Effect of audience response system technology on learning outcomes in health students and professionals: an updated systematic review. International Journal of Evidence Based Healthcare, 13, 3-8.

AZER, S. A. \& EIZENBERG, N. 2007. Do we need dissection in an integrated problem-based learning medical course? Perceptions of first- and second-year students. Surg Radiol Anat, 29, 17380.

BIRT, J., MOORE, E. \& COWLING, M. 2017. Improving paramedic distance education through mobile mixed reality simulation. Australasian Journal of Educational Technology, 33.

BIRT, J., STROMBERGA, Z., COWLING, M. \& MORO, C. 2018. Mobile Mixed Reality for Experiential Learning and Simulation in Medical and Health Sciences Education. Information, 9, 31.

BOYLE, E. A., HAINEY, T., CONNOLLY, T. M., GRAY, G., EARP, J., OTT, M., LIM, T., NINAUS, M., RIBEIRO, C. \& PEREIRA, J. 2016. An update to the systematic literature review of empirical evidence of the impacts and outcomes of computer games and serious games. Computers \& Education, 94, 178-192.

BRIZ-PONCE, L. \& GARCÍA-PEÑALVO, F. J. J. J. O. M. S. 2015. An Empirical Assessment of a Technology Acceptance Model for Apps in Medical Education. Journal of Medical Systems, 39, 176.

CAI, B., RAJENDRAN, K., BAY, B. H., LEE, J. \& YEN, C. C. 2018. The Effects of a Functional Threedimensional (3D) Printed Knee Joint Simulator in Improving Anatomical Spatial Knowledge. Anat Sci Educ. 
CHESTON, C. C., FLICKINGER, T. E. \& CHISOLM, M. S. 2013. Social Media Use in Medical Education: A Systematic Review. Academic Medicine, 88, 893-901.

CHUGH, R. \& RUHI, U. 2018. Social media in higher education: A literature review of Facebook. Education and Information Technologies, 23, 605-616.

COOK, D. A., ERWIN, P. J. \& TRIOLA, M. M. 2010a. Computerized Virtual Patients in Health Professions Education: A Systematic Review and Meta-Analysis. Academic Medicine, 85, 1589-1602.

COOK, D. A., GARSIDE, S., LEVINSON, A. J., DUPRAS, D. M. \& MONTORI, V. M. 2010b. What do we mean by web-based learning? A systematic review of the variability of interventions. Medical Education, 44, 765-774.

COOK, D. A., HATALA, R., BRYDGES, R., ZENDEJAS, B., SZOSTEK, J. H., WANG, A. T., ERWIN, P. J. \& HAMSTRA, S. J. 2011. Technology-Enhanced Simulation for Health Professions Education: A Systematic Review and Meta-analysis. JAMA, 306, 978-988.

COWLING, M. \& MORO, C. 2019. Holographic teachers were supposed to be part of our future. What happened? The Conversation, January 8, 2019.

CUSTER, T. \& MICHAEL, K. 2015. The Utilization of the Anatomage Virtual Dissection Table in the Education of Imaging Science Students. Journal Articles: Radiation Science Technology Education, 1, 1-5.

DELELLO, J. A., MCWHORTER, R. R. \& CAMP, K. M. 2015. Integrating Augmented Reality in Higher Education: A Multidisciplinary Study of Student Perceptions. Journal of Educational Multimedia and Hypermedia, 24, 209-233.

DONG, C. \& GOH, P. S. 2015. Twelve tips for the effective use of videos in medical education. Medical Teacher, 37, 140-145.

DUNCAN, I., YARWOOD-ROSS, L. \& HAIGH, C. 2013. YouTube as a source of clinical skills education. Nurse Education Today, 33, 1576-1580.

GENTRY, S. V., GAUTHIER, A., L'ESTRADE EHRSTROM, B., WORTLEY, D., LILIENTHAL, A., TUDOR CAR, L., DAUWELS-OKUTSU, S., NIKOLAOU, C. K., ZARY, N., CAMPBELL, J. \& CAR, J. 2019. Serious Gaming and Gamification Education in Health Professions: Systematic Review. J Med Internet Res, 21, e12994.

GEORGE, P. P., PAPACHRISTOU, N., BELISARIO, J. M., WANG, W., WARK, P. A., COTIC, Z., RASMUSSEN, K., SLUITER, R., RIBOLI-SASCO, E., TUDOR CAR, L., MUSULANOV, E. M., MOLINA, J. A., HENG, B. H., ZHANG, Y., WHEELER, E. L., AL SHORBAJI, N., MAJEED, A. \& CAR, J. 2014. Online eLearning for undergraduates in health professions: A systematic review of the impact on knowledge, skills, attitudes and satisfaction. Journal of global health, 4, 010406-010406.

GIRARD, C., ECALLE, J. \& MAGNAN, A. 2013. Serious games as new educational tools: how effective are they? A meta-analysis of recent studies. Journal of Computer Assisted Learning, 29, 207219.

GORBANEV, I., AGUDELO-LONDOÑO, S., GONZÁLEZ, R. A., CORTES, A., POMARES, A., DELGADILLO, V., YEPES, F. J. \& MUÑOZ, Ó. 2018. A systematic review of serious games in medical education: quality of evidence and pedagogical strategy. Medical Education Online, 23, 1438718.

GOUGH, S. 2018. Educating for professional practice through simulation. In: DELANY, C. \& MOLLOY, E. (eds.) Learning and teaching in clinical contexts : a practical guide

Chatswood, NSW: Elsevier.

GOUGH, S., YOHANNES, A. M. \& MURRAY, J. 2016. Using video-reflexive ethnography and simulation-based education to explore patient management and error recognition by preregistration physiotherapists. Adv Simul (Lond), 1, 9.

GOUGH, S., YOHANNES, A. M., THOMAS, C. \& SIXSMITH, J. 2013. Simulation-based education (SBE) within postgraduate emergency on-call physiotherapy in the United Kingdom. Nurse Educ Today, 33, 778-84. 
HANSON, C., WEST, J., NEIGER, B., THACKERAY, R., BARNES, M. \& MCINTYRE, E. 2011. Use and Acceptance of Social Media Among Health Educators. American Journal of Health Education, 42, 197-204.

HOSSEINI, F., OBEROI, V., DOROUDI, M. \& VO, L. 2018. A Visual Guide to Foregut anatomy: Using Digital Multimedia to Enhance the Learning of Human Gross Anatomy. The FASEB Journal, 32, 635.27-635.27.

HUNSU, N. J., ADESOPE, O. \& BAYLY, D. J. 2016. A meta-analysis of the effects of audience response systems (clicker-based technologies) on cognition and affect. Computers \& Education, 94, 102-119.

JAYAKUMAR, N., BRUNCKHORST, O., DASGUPTA, P., KHAN, M. S. \& AHMED, K. 2015. e-Learning in Surgical Education: A Systematic Review. Journal of Surgical Education, 72, 1145-1157.

JENSON, C. E. \& FORSYTH, D. M. 2012. Virtual reality simulation: using three-dimensional technology to teach nursing students. Comput Inform Nurs, 30, 312-8; quiz 319-20.

JIN, W., BIRCKHEAD, B., PEREZ, B. \& HOFFE, S. 2017. Augmented and virtual reality: Exploring a future role in radiation oncology education and training. Appl Rad Oncol, 6, 13-20.

JONES, D. B., SUNG, R., WEINBERG, C., KORELITZ, T. \& ANDREWS, R. 2016. Three-Dimensional Modeling May Improve Surgical Education and Clinical Practice. Surgical Innovation, 23, 189195.

KILMON, C. A., BROWN, L., GHOSH, S. \& MIKITIUK, A. 2010. Immersive Virtual Reality Simulations in Nursing Education. Nursing Education Perspectives, 31, 314-317.

KIM, J. H. \& PARK, H. 2019. Effects of Smartphone-Based Mobile Learning in Nursing Education: A Systematic Review and Meta-analysis. Asian Nursing Research, 13, 20-29.

KLÍMOVÁ, B. 2018. Mobile Learning in Medical Education. Journal of Medical Systems, 42, 194.

KNIGHT, J. F., CARLEY, S., TREGUNNA, B., JARVIS, S., SMITHIES, R., DE FREITAS, S., DUNWELL, I. \& MACKWAY-JONES, K. 2010. Serious gaming technology in major incident triage training: A pragmatic controlled trial. Resuscitation, 81, 1175-1179.

KUEHN, B. M. 2018. Virtual and Augmented Reality Put a Twist on Medical Education. JAMA, 319, 756-758.

LALL, P., REES, R., LAW, G. C. Y., DUNLEAVY, G., COTIČ, Ž. \& CAR, J. J. J. O. M. I. R. 2019. Influences on the implementation of mobile learning for medical and nursing education: Qualitative systematic review by the Digital Health Education Collaboration. 21, e12895.

LIM, K. H. A., LOO, Z. Y., GOLDIE, S. J., ADAMS, J. W. \& MCMENAMIN, P. G. 2016. Use of 3D printed models in medical education: A randomized control trial comparing 3D prints versus cadaveric materials for learning external cardiac anatomy. Anatomical Sciences Education, 9, 213-221.

LIU, C., CHEN, X., LIU, S., ZHANG, X., DING, S., LONG, Y. \& ZHOU, D. The Exploration on Interacting Teaching Mode of Augmented Reality Based on HoloLens. In: CHEUNG, S. K. S., JIAO, J., LEE, L.-K., ZHANG, X., LI, K. C. \& ZHAN, Z., eds. Technology in Education: Pedagogical Innovations, 2019// 2019 Singapore. Springer Singapore, 91-102.

MAERTENS, H., MADANI, A., LANDRY, T., VERMASSEN, F., VAN HERZEELE, I. \& AGGARWAL, R. 2016. Systematic review of e-learning for surgical training. The British Journal of Surgery, 103, 1428-1437.

MALIK, H. H., DARWOOD, A. R. J., SHAUNAK, S., KULATILAKE, P., EL-HILLY, A. A., MULKI, O. \& BASKARADAS, A. 2015. Three-dimensional printing in surgery: a review of current surgical applications. Journal of Surgical Research, 199, 512-522.

MATHIOWETZ, V., YU, C. H. \& QUAKE-RAPP, C. 2016. Comparison of a gross anatomy laboratory to online anatomy software for teaching anatomy. Anat Sci Educ, 9, 52-9.

MCCALLUM, S. 2012. Gamification and serious games for personalized health. Stud Health Technol Inform, 177, 85-96.

MCGAGHIE, W. C., ISSENBERG, S. B., PETRUSA, E. R. \& SCALESE, R. J. 2010. A critical review of simulation-based medical education research: 2003-2009. Medical Education, 44, 50-63. 
MCGAGHIE, W. C., ISSENBERG, S. B., PETRUSA, E. R. \& SCALESE, R. J. 2016. Revisiting 'A critical review of simulation-based medical education research: 2003-2009'. Medical Education, 50, 986-991.

MILLER, L. M., CHANG, C.-I., WANG, S., BEIER, M. E. \& KLISCH, Y. 2011. Learning and motivational impacts of a multimedia science game. Computers \& Education, 57, 1425-1433.

MOORHEAD, S. A., HAZLETT, D. E., HARRISON, L., CARROLL, J. K., IRWIN, A. \& HOVING, C. 2013. A new dimension of health care: systematic review of the uses, benefits, and limitations of social media for health communication. Journal of medical Internet research, 15, e85-e85.

MORO, C. \& GREGORY, S. 2019. Utilising Anatomical and Physiological Visualisations to Enhance the Face-to-Face Student Learning Experience in Biomedical Sciences and Medicine. Adv Exp Med Biol, 1156, 41-48.

MORO, C. \& HENSEN, D. 2017. Engaging timid students: Backchannel as a tool to provide opportunities for interactivity and engagement within the university classroom. Education Technology Solutions.

MORO, C. \& KINASH, S. 2012. Developing online worksheets that work. Educational Technology Solutions.

MORO, C. \& MCLEAN, M. 2017. Supporting Students' Transition to University and Problem-Based Learning. Medical Science Educator, 27, 353-361.

MORO, C. \& PERIYA, S. 2019. Applied Learning of Anatomy and Physiology: Virtual Dissection Tables within Medical and Health Sciences Education. Bangkok Medical Journal, 15, 121-127.

MORO, C., SPOONER, A. \& MCLEAN, M. 2019. How prepared are students for the various transitions in their medical studies? An Australian university pilot study. MedEdPublish, 8, 25.

MORO, C., STROMBERGA, Z., RAIKOS, A. \& STIRLING, A. 2017a. The effectiveness of virtual and augmented reality in health sciences and medical anatomy. Anat Sci Educ, 10, 549-559.

MORO, C., STROMBERGA, Z. \& STIRLING, A. 2017b. Virtualisation devices for student learning: Comparison between desktop-based (Oculus Rift) and mobile-based (Gear VR) virtual reality in medical and health science education. 2017, 33.

NARNAWARE, Y. \& NEUMEIER, M. 2019. Second-Year Nursing Students' Retention of Gross Anatomical Knowledge. Anatomical Sciences Education, 0.

NELSON, C., HARTLING, L., CAMPBELL, S. \& OSWALD, A. E. 2012. The effects of audience response systems on learning outcomes in health professions education. A BEME systematic review: BEME Guide No. 21. Medical Teacher, 34, e386-e405.

O'CONNOR, S. \& ANDREWS, T. 2015. Mobile technology and its use in clinical nursing education: a literature review. J Nurs Educ, 54, 137-44.

O'CONNOR, S., JOLLIFFE, S., STANMORE, E., RENWICK, L. \& BOOTH, R. 2018. Social media in nursing and midwifery education: A mixed study systematic review. Journal of Advanced Nursing, 74, 2273-2289.

OWEN, H. 2016. Simulation in Healthcare Education. An Extensive History. The Obstetrician \& Gynaecologist, 18, 330-330.

PETIT DIT DARIEL, O. J., RABY, T., RAVAUT, F. \& ROTHAN-TONDEUR, M. 2013. Developing the Serious Games potential in nursing education. Nurse Educ Today, 33, 1569-75.

PIMMER, C., MATEESCU, M. \& GRÖHBIEL, U. 2016. Mobile and ubiquitous learning in higher education settings. A systematic review of empirical studies. Computers in Human Behavior, 63, 490-501.

RAMSEY-STEWART, G., BURGESS, A. W. \& HILL, D. A. 2010. Back to the future: teaching anatomy by whole-body dissection. Med J Aust, 193, 668-71.

RICCIARDI, F. \& DE PAOLIS, L. T. 2014. A Comprehensive Review of Serious Games in Health Professions. International Journal of Computer Games Technology, 2014, 11.

ROBERT, P., KÖNIG, A., AMIEVA, H., ANDRIEU, S., BREMOND, F., BULLOCK, R., CECCALDI, M., DUBOIS, B., GAUTHIER, S., KENIGSBERG, P.-A., NAVE, S., ORGOGOZO, J. M., PIANO, J., BENOIT, M., TOUCHON, J., VELLAS, B., YESAVAGE, J. \& MANERA, V. 2014. Recommendations for the use 
of Serious Games in people with Alzheimer's Disease, related disorders and frailty. Frontiers in Aging Neuroscience, 6.

STERLING, M., LEUNG, P., WRIGHT, D. \& BISHOP, T. F. 2017. The Use of Social Media in Graduate Medical Education: A Systematic Review. Academic Medicine, 92, 1043-1056.

STIRLING, A. \& BIRT, J. 2014. An enriched multimedia eBook application to facilitate learning of anatomy. Anatomical Sciences Education, 7, 19-27.

SU, W., XIAO, Y., HE, S., HUANG, P. \& DENG, X. 2018. Three-dimensional printing models in congenital heart disease education for medical students: a controlled comparative study. BMC medical education, 18, 178-178.

SURAL, I. 2018. Augmented Reality Experience: Initial Perceptions of Higher Education Students. International Journal of Instruction, 11, 565-576.

SUTHERLAND, J., BELEC, J., SHEIKH, A., CHEPELEV, L., ALTHOBAITY, W., CHOW, B. J. W., MITSOURAS, D., CHRISTENSEN, A., RYBICKI, F. J. \& LA RUSSA, D. J. 2019. Applying Modern Virtual and Augmented Reality Technologies to Medical Images and Models. Journal of Digital Imaging, 32, 38-53.

TUONG, W., LARSEN, E. R. \& ARMSTRONG, A. W. J. J. O. B. M. 2014. Videos to influence: a systematic review of effectiveness of video-based education in modifying health behaviors. Journal of Behavioral Medicine, 37, 218-233.

WANG, R., DEMARIA, S., JR., GOLDBERG, A. \& KATZ, D. 2016. A Systematic Review of Serious Games in Training Health Care Professionals. Simul Healthc, 11, 41-51.

WINKELMANN, A. 2007. Anatomical dissection as a teaching method in medical school: a review of the evidence. Med Educ, 41, 15-22.

WONG, G., GREENHALGH, T. \& PAWSON, R. J. B. M. E. 2010. Internet-based medical education: a realist review of what works, for whom and in what circumstances. BMC Medical Education, $10,12$. 